mental healthcare, victim services, foster care, police services, perpetrator treatment, adjudication, sanctioning and victim loss of wages and quality of life. Quality of life losses were estimated from lawsuits against third parties who failed to secure and illuminate their premises or served alcohol to an already-intoxicated person prior to an assault. We estimated probabilities and costs of sexually transmitted illnesses, unplanned pregnancies and (based on studies of twins) of youth victimisation causing suicide acts or substance abuse. Unit costs came from crime surveys, healthcare data, state sanctioning budgets, and published literature. In 2005, for example, 61000 Minnesota residents were sexually assaulted, suffering an average of 1.26 assaults per victim. Police logged 7200 reports of unwanted sexual intercourse, but only 2617 met the law enforcement definition of rape. Consequently, most police-reported rapes were omitted from state rape statistics. (Michigan's definition created less undercounting.) Sexual violence costs 3.3 times as much as alcohol-impaired driving in Minnesota. Costs totalled $\$ 8$ billion in 2005 , or $\$ 1540$ per resident. Quality of life losses of victims and their families and related breakdowns in their lives and relationships wee the largest costs. Criminal justice and perpetrator treatment cost $\$ 130$ million. Other direct spending totalled $\$ 1.3$ billion. State government spent $\$ 130$ million on sexual violence perpetrators and $\$ 90$ million on victims. More resources are needed for sexual assault prevention and victim assistance. Our methods are replicable.

\title{
0678 IN THE UNITED STATES, SEXUAL VIOLENCE COSTS MORE THAN DRUNK DRIVING
}

TR Miller*, D M Taylor, M Sheppard Correspondence: Pacific Institute for Research \& Evaluation, 11720 Beltsville Drive, \#900 Calverton, MD 20705, USA

10.1136/ip.2010.029215.678

We estimated costs of sexual violence in selected states and are making a national estimate. Cost categories include medical care, 